\title{
A Lei n. 12.244 e sua concepção de biblioteca escolar: uma análise
}

\author{
Fabíola Ribeiro Farias \\ Universidade Federal do Oeste do Pará, Instituto de Ciências da Educação, Santarém, PA, Brasil \\ fabirfarias@yahoo.com.br \\ Luiz Percival Leme Britto \\ Universidade Federal do Oeste do Pará, Instituto de Ciências da Educação, Santarém, PA, Brasil \\ luizpercival@hotmail.com
}

DOI: https://doi.org/10.26512/rici.v12.n3.2019.19155

\section{Recebido/Recibido/Received: \\ Aceitado/Aceptado/Accepted:}

Resumo: $O$ artigo propõe uma análise da Lei n. 12.244, que dispõe sobre a obrigatoriedade de bibliotecas escolares nas instituições de ensino, públicas e privadas, brasileiras à luz de dois aspectos que tocam seu objeto: a perspectiva educacional e as recomendações biblioteconômicas. Para isso, considera os pressupostos teóricos da pedagogia histórico-crítica e os documentos sobre o tema produzidos e divulgados pelo Conselho Federal de Biblioteconomia. Constata, no texto da Lei, a ausência de proposição de trabalho educativo na biblioteca escolar e a fragilidade conceitual em suas exigências, concluindo por sua pouca efetividade na formação escolar.

Palavras-chave. Biblioteca escolar. Legislação. Trabalho educativo. Pedagogia. Lei n. 12.244/2010.

\section{Law n. 12.244 and its conception of school library: an analysis}

Abstract: The article proposes an analysis of Law 12.244, which deals with the obligatory nature of school libraries in public and private Brazilian educational institutions in the light of two aspects that touch on its object: the educational perspective and the librarians' recommendations. For this, it considers the theoretical assumptions of historical-critical pedagogy and the documents on the theme produced and disseminated by the Federal Library Board. It notes the absence of a proposal of educational work in the school library present in the Law and conceptual fragility in its demands, concluding for its low effectiveness in school education.

Keywords. School library. Legislation. Educational work. Pedagogy. Law n. 12.244/2010.

\section{La Ley n. 12.244 y su concepción de biblioteca escolar: un análisis}

Resumen: El artículo propone un análisis de la Ley 12.244, que dispone sobre la obligatoriedad de bibliotecas escolares en las instituciones de enseñanza, públicas y privadas, brasileñas a la luz de dos aspectos que tocan su objeto: la perspectiva educativa y las recomendaciones bibliotecarias. Para ello, considera las pautas teóricas de la Pedagogía Histórico-crítica y los documentos sobre el tema producidos y divulgados por el Consejo Federal de Biblioteconomía. Constata, en el texto de la Ley, la ausencia de proposición de trabajo educativo en la biblioteca escolar y la debilidad conceptual en cuanto a sus exigencias, concluyendo por su poca efectividad en la formación escolar.

Palabras clave: Biblioteca escolar. Legislación. Trabajo educativo. Pedagogía. Ley n. 12.244/2010. 


\section{Introdução}

No dia 24 de maio de 2010, o Diário Oficial da União publica a Lei n. 12.244, que dispõe sobre a universalização das bibliotecas nas instituições de ensino do País. Sintético, o texto da Lei apresenta quatro artigos que, em resumo, obrigam as instituições públicas e privadas de ensino a dispor de bibliotecas; definem biblioteca escolar; recomendam o esforço dos sistemas de ensino do País para que a Lei seja efetivada no prazo máximo de dez anos; e resguardam a determinação legal que regulamenta a profissão do bibliotecário.

A existência de bibliotecas nas instituições de ensino é inquestionável para a ampliação do acesso ao livro e à leitura no País e condição, embora não garantia, de participação de crianças, adolescentes e educadores no conhecimento sistematizado, motivo pelo qual o sancionamento da Lei pode ser compreendido como uma conquista no campo da Educação e da Cultura.

No entanto, aspectos do texto demandam esclarecimentos e se abrem a críticas, uma vez que criam lacunas para que, cumprida, a lei não seja capaz, efetivamente, de promover a cultura escrita e o espírito investigativo nas escolas.

Neste trabalho, analisamos os três primeiros artigos da Lei n. 12.244 (o quarto apenas estabelece que a Lei entraria em vigor na data de sua publicação), no que toca à concepção da biblioteca escolar, incluindo a formação de seu acervo, a oferta de serviços, a proposição de atividades e a exigência do profissional bibliotecário.

O fato de ter como objeto bibliotecas em instituições de ensino, isto é, bibliotecas escolares, é imprescindível que a análise do referido ato legal seja feita à luz de um projeto de Educação, junto a recomendações da área de Biblioteconomia. Isso porque é necessário que a biblioteca escolar esteja ancorada em um horizonte educacional, alinhada com o projeto político pedagógico da escola e atenda às recomendações biblioteconômicas para seu adequado funcionamento.

A análise será realizada a partir de duas perspectivas: uma a partir da concepção de trabalho educativo da Pedagogia Histórico-crítica; e a outra, considerando as recomendações da Resolução CFB N. 199/2018¹ , publicada no Diário Oficial da União em 13/7/2018, que dispõe sobre os parâmetros a serem adotados na estruturação e no funcionamento das bibliotecas escolares, contemplando dois aspectos que definem a atuação da biblioteca escolar: sua concepção político-pedagógica e suas características técnicas. Os dois aspectos são

1 A Resolução CFB N. 199/2018 derroga a Resolução CFB N. 119/2011, em que a instituição tomava como parâmetros para as bibliote cas escolares o documento Biblioteca escolar como espaço de produção do conhecimento: parâmetros para bibliotecas escolares, do Grupo de Estudos em Biblioteca Escolar da Escola de Ciência da Informação da Universidade Federal de Minas Gerais. 
indissociáveis, pois se complementam, criando condições para a ação pedagógica e bibliotecária na escola, divisão aqui realizada para fins meramente didáticos deste estudo.

\section{Os parâmetros para estruturação e funcionamento de bibliotecas escolares estabelecidos pelo Conselho Federal de Biblioteconomia}

O Conselho Federal de Biblioteconomia (CFB), personalidade jurídica de direito público com autonomia administrativa e patrimonial, foi criado pela Lei n. 40.084, de 30/6/1962, que dispõe sobre a profissão de bibliotecário e regula seu exercício. Dentre suas atribuições, estão a expedição de resoluções que se tornem necessárias à fiel interpretação e execução da supracitada lei, a proposição ao Governo Federal de modificações para melhorar a regulamentação do exercício do profissional bibliotecário e a deliberação sobre questões oriundas do exercício de atividades afins à especialidade do bibliotecário.

É nesse contexto que se insere a Resolução n. 199/2018, que dispõe sobre os parâmetros para estruturação e funcionamento das bibliotecas escolares, em consonância com a Lei de Diretrizes e Bases da Educação Nacional (Lei n. 9.394/96).

Segundo o documento, a biblioteca escolar é compreendida como "[...] coleção de livros, materiais videográficos e documentos registrados em qualquer suporte destinados a consulta, pesquisa, estudo ou leitura, sendo considerado um dispositivo informacional obrigatório em todas as instituições de ensino públicas e privadas do Sistema de Ensino" (CONSELHO FEDERAL DE BIBLIOTECONOMIA, 2018) e deve:

a) dispor de espaço físico exclusivo e suficiente para acomodar o acervo, os ambientes para serviços e atividades dos usuários e os serviços técnico administrativos;

b) possuir materiais informacionais atualizados e diversificados, que atendam às necessidades dos usuários;

c) ter acervo organizado de acordo com as normas e padrões biblioteconômicos, permitindo que os materiais sejam encontrados com facilidade e rapidez;

d) disponibilizar acesso a informações digitais (Internet);

e) funcionar como espaço de aprendizagem;

f) serem administradas por bibliotecários qualificados, apoiados por equipes adequadas em quantidade e qualificação para atenderem à comunidade.

g) ter horário de atendimento adequado a toda a comunidade escolar, de forma a estar disponível a seus usuários também em horários de intervalo, a fim de proporcionar acesso à informação de forma irrestrita. (CONSELHO FEDERAL DE BIBLIOTECONOMIA, 2018)

No que toca ao espaço físico, primeiro item da composição da biblioteca escolar no documento, as recomendações apontam para área mínima de $50 \mathrm{~m}^{2}$, com mobiliário e equipamentos satisfatórios ao atendimento da comunidade escolar. Não há no texto menção a 
proporcionalidade na relação entre espaço físico e número de alunos, restando apenas o tamanho mínimo.

Ao dispor sobre o acervo, a primeira orientação diz respeito ao número de itens, com a recomendação expressa de, no mínimo, dez títulos por aluno, contemplando "[...] a diversidade de gêneros e estilos literários, com autores nacionais e estrangeiros" (CONSELHO FEDERAL DE BIBLIOTECONOMIA, 2018). Embora não seja mencionada, a referência quantitativa para a formação do acervo na relação com o número de alunos parece ter sido tomada do "Manifesto para as Bibliotecas Escolares da IFLA/Unesco"2, documento de ampla circulação quando se trata de bibliotecas escolares, que estabelece, ainda, acervo mínimo de 2.500 títulos para escolas pequenas. Há, ademais, a recomendação de que o acervo contemple materiais informativos atualizados, impressos e não impressos, tais como livros, periódicos, atlas, enciclopédias, almanaques e dicionários, que sirvam de subsídios à pesquisa escolar. Todo o acervo deve estar catalogado, tendo em vista o atendimento às necessidades e à realidade dos usuários.

As recomendações relativas aos serviços e atividades da biblioteca abrangem a consulta local ao acervo, o empréstimo domiciliar, as atividades de incentivo à leitura e o apoio à pesquisa escolar, sem qualquer especificação ou detalhamento.

No que toca aos recursos humanos, o documento determina a presença obrigatória de um bibliotecário supervisor, que pode ser responsável pela coordenação de até quatro bibliotecas, admitida a implantação de "espaços de leitura" nas escolas nucleadas, desde que sob a orientação da Escola Polo.

Um item específico trata das orientações de guarda, preservação, organização e funcionamento das bibliotecas escolares.

O documento traz ainda orientações de garantia de acessibilidade, compreendida como

[...] possibilidade e condição de alcance, percepção e entendimento para utilização, com segurança e autonomia de espaços, mobiliários, equipamentos urbanos, edificações, transportes, acesso à informação e comunicação, incluindo seus sistemas e tecnologias ou elemento que possa ser alcançado, acionado, utilizado e vivenciado por qualquer pessoa em conformidade com a NBR 9050 . (CONSELHO FEDERAL DE BIBLIOTECONOMIA, 2018)

Especificamente em relação aos parâmetros de acessibilidade, há no documento a ressalva de que poderão ser revistos pelo Conselho Federal de Biblioteconomia, mas sem explicações sobre suas motivações.

\footnotetext{
${ }^{2}$ A Federação Internacional de Associações e Instituições Bibliotecárias é um organismo internacional que representa os interesses dos serviços de biblioteca e informação e dos seus usuários, criada em 1927 no Reino Unido.

${ }^{3}$ A ABNT-NBR 9050 dispõe sobre acessibilidade a edificações, mobiliário, espaços e equipamentos urbanos.
} 
A Resolução reforça a recomendação legal de que os Sistemas de Ensino da Educação Básica devem se esforçar para viabilizar financeiramente a implementação da lei, observados os parâmetros apresentados e o prazo limite de 31/12/2020.

A Resolução 199/2018 valida quase que integralmente o documento Biblioteca escolar como espaço de produção do conhecimento: parâmetros para bibliotecas escolares, do Grupo de Estudos em Biblioteca Escolar da Escola de Ciência da Informação da Universidade Federal de Minas Gerais, referência na derrogada Resolução 119/2011. Esse documento estabelece parâmetros quantitativos para o que considera, sem justificativa, níveis básico e exemplar, limitando-se a afirmar que o primeiro é um "ponto de partida" e o segundo "um horizonte a ser alcançado". As diferenças entre os dois documentos estão na ausência de especificações quantitativas a ser alcançadas em níveis básico e exemplar.

\section{A Pedagogia Histórico-crítica e o trabalho educativo}

A pedagogia histórico-crítica surgiu no final da década de 1970 como proposição de resposta e intervenção frente às conclusões das teorias crítico-reprodutivistas no campo da Educação. Estas apontavam a escola como instrumento de reprodução simbólica dos interesses das classes dominantes e constatavam a impossibilidade de se alterarem as estruturas sociais por meio da revolução cultural, uma vez que "[...] a cultura (e, em seu bojo, a educação) é um fenômeno superestrutural; integra, pois, a instância ideológica, sendo assim determinado pela base material. Portanto, não tem o poder de alterar a base material." (SAVIANI, 2013, p. 58).

Naquele contexto, na França, os estudos de Althusser postulavam a escola como aparelho ideológico do Estado e os de Bourdieu e Passeron reafirmavam seu lugar de violência simbólica, que escamoteava a reprodução de valores e crenças e criava as bases culturais e ideológicas para a manutenção do status quo. Dito de outra maneira, a escola reproduzia e legitimava, de forma mais ou menos velada, as mentalidades que sustentavam a dominação, uma vez que as condições sociais, econômicas e culturais de estudantes e docentes se mostravam impedimento à compreensão da especificidade da educação e das relações de produção, inclusive na própria escola.

No Brasil, a leitura de tais autores foi fundamental na percepção aprofundada do regime autoritário e especialmente de seus desdobramentos na escola. As teorias críticoreprodutivistas sustentaram pesquisas brasileiras e evidenciaram aspectos educacionais pouco visíveis, mas se mostraram insuficientes na proposição de uma ação pedagógica. Se, por um lado, expunham considerável gama de problemas, por outro não apresentavam propostas de intervenção no cenário que descortinavam: 
Progressivamente, no entanto, foram tornando-se cada vez mais evidentes os limites da teoria crítico-reprodutivista. Ela revela-se capaz de fazer a crítica do existente, de explicitar os mecanismos do existente, mas não tem proposta de intervenção prática, isto é, limita-se a constatar e, mais do que isso, a constatar que é assim e não pode ser de outro modo. O problema, no entanto, que os educadores enfrentavam extrapolava esse âmbito, porque a questão central era justamente como atuar de modo crítico no campo pedagógico, como ser um professor que, ao agir, desenvolve uma prática de caráter crítico. (SAVIANI, 2013, p. 58-59)

A pedagogia histórico-crítica surge do anseio de intervenção pedagógica em um cenário dado como determinado. Ancorado pelo exercício dialético e compreendendo a educação como processo contraditório, Saviani (2013) acrescenta seu revés à perspectiva da escola como instrumento de reprodução de interesses das classes dominantes, isto é, a escola como possibilidade de luta das classes populares contra as dominantes.

Assim, a pedagogia histórico-crítica estabelece suas bases no entendimento da Educação como trabalho imaterial, em que o produto não se separa do ato de produção, com a especificidade de ser produção humana, algo que não é dado espontaneamente:

O que não é garantido pela natureza tem que ser produzido historicamente pelos homens, e aí se incluem os próprios homens. Podemos, pois, dizer que a natureza humana não é dada ao homem, mas é por ele produzida sobre a base da natureza biofísica. Consequentemente, o trabalho educativo é o ato de produzir, direta e intencionalmente, em cada indivíduo singular, a humanidade que é produzida histórica e coletivamente pelo conjunto dos homens. Assim, o objeto da educação diz respeito, de um lado, à identificação dos elementos culturais que precisam ser assimilados pelos indivíduos da espécie humana para que eles se tornem humanos e, de outro lado e concomitantemente, à descoberta das formas mais adequadas para atingir esse objetivo. (SAVIANI, 2013, p. 13)

Nessa perspectiva, o autor distingue o tipo de saber a ser socializado na escola, priorizando o saber sistematizado ao espontâneo, a cultura erudita à cultura popular. Para ilustrar tal proposição, vale-se de três palavras gregas referentes ao conhecimento: doxa, sofia e episteme: doxa designa opinião, o saber do senso comum, diretamente vinculado à experiência da vida cotidiana; sofia é relacionada à experiência construída ao longo da vida, à tradição; e episteme refere-se à ciência, ao conhecimento metódico, sistematizado.

De acordo com Saviani (2013), os conhecimentos da opinião e da experiência vivida doxa e sofia - não justificam, até dispensam, a existência da escola, pois são adquiridos espontaneamente nas relações familiares e sociais. Segundo o autor, a escola existe para criar as condições de aquisição do saber sistematizado, da ciência e seus rudimentos, ou seja, a episteme, tendo como primeira exigência a leitura e a escrita, mas também a linguagem dos números, da natureza e da sociedade. 
Antecipando-se à objeção que problematiza a hierarquização, na educação escolar, da cultura formal sobre a popular, Saviani (2013) observa que ambas são produzidas historicamente, mas que a primeira não pode ser apropriada espontaneamente, como ocorre com a segunda. Como as classes dominantes, por condições materiais, se apropriam mais facilmente da cultura erudita, caberia à escola criar as condições para que as classes populares possam se educar nessa perspectiva:

[...] chamo a atenção para o fato de que o saber é histórico, e como tal é apropriado pelas classes dominantes, mas isso não significa que ele seja inerentemente dominante. O que hoje é denominado "saber burguês" é um saber do qual a burguesia se apropriou e colocou a serviço de seus interesses. Em suma, o que parece importante entender é o seguinte: essa dicotomia entre saber erudito como saber da dominação e saber popular como saber autêntico próprio da libertação é uma dicotomia falsa. Nem o saber erudito é puramente burguês, dominante, nem a cultura popular é puramente popular. A cultura popular incorpora elementos da ideologia e da cultura dominantes que, ao se converterem em senso comum, penetram nas massas. (SAVIANI, 2013, p. 69)

De maneira resumida, a sustentação do trabalho educativo da Pedagogia Históricocrítica está em garantir à população o conhecimento produzido historicamente, sistematizado, de maneira a possibilitar a compreensão, individual e coletiva, do tempo, do espaço e das relações sociais, econômicas e culturais que determinam o modo de viver, pensar e produzir de cada grupo social. Isso implica, obviamente, a exposição de conflitos, contradições e convergências em distintos campos do conhecimento e sistemas de pensamento.

Cabe ressaltar que a pedagogia histórico-crítica não se dedicou a pensar, especificamente, a leitura, a escrita e as bibliotecas; sua concepção de trabalho educativo está sendo utilizada nesta reflexão como ancoragem de um horizonte educacional.

\section{Leitura crítica da Lei n. 12.244/10}

A crítica à Lei n. 12.244/2010, conforme proposição deste artigo, será feita à luz da pedagogia histórico-crítica e sua concepção de trabalho educativo e da Resolução CFB n. 199/2018, que, a partir das atribuições legais da instituição, estabelece os parâmetros para a estruturação e o funcionamento das bibliotecas escolares no País.

O primeiro ponto a ser problematizado é a concepção de biblioteca escolar presente na Lei e validada pela Resolução, que reduz a biblioteca escolar ao acervo e à presença obrigatória do profissional bibliotecário. Como já especifica o nome, a biblioteca escolar faz parte da escola e, nessa condição, deve estar integrada à sua dinâmica, participando dos processos pedagógicos, de sua proposição, execução e avaliação. A Lei em questão parece desconhecer essa condição 
de origem, uma vez que seu texto não valoriza ou garante qualquer laço com a escola como um todo e com um projeto de educação. E isso fica evidente quando se constata, no corpo da Lei, ausência de termos como projeto pedagógico, currículo, pesquisa, formação, serviços, atividades, dentre outros que sinalizassem a preocupação com o trabalho educativo da biblioteca.

A Resolução CFB n. 199/2018 valida a concepção de biblioteca presente na Lei, apresentando o mesmo texto de definição, acrescentando sua obrigatoriedade em todas as instituições públicas e privadas do Sistema de Ensino e a considerando dispositivo informacional, sem explicar ou apresentar referências para a compreensão do termo ${ }^{4}$.

No que toca ao acervo, a recomendação legal se restringe ao aspecto quantitativo, desconsiderando qualquer orientação à sua constituição. A obrigação é de que as bibliotecas escolares contem com, no mínimo, um título por aluno, não importando o tamanho da escola e de seus corpos discente e docente. A resolução acompanha a recomendação legal, mas afirma a importância de se contemplar a diversidade de gêneros literários, de autores brasileiros e estrangeiros, de obras informativas e de referência, em formatos impresso e eletrônico, além de prever a ampliação e o tratamento do acervo.

O primeiro problema a ser observado é o cálculo do tamanho do acervo, sustentado na relação de um título por aluno. Nem a Lei, nem a Resolução apresentam que entendimento baliza essa recomendação. Em uma escola pequena, com número reduzido de alunos, o acervo da biblioteca pode estar condenado a uma limitação indesejável, que compromete a produção do conhecimento e a criação literária na formação de estudantes e educadores.

Na perspectiva do trabalho educativo da pedagogia histórico-crítica, que é a de criar condições para que os educandos se reconheçam, individual e coletivamente, em sua historicidade a partir do conhecimento sistematizado, científico, e também da produção literária, a contribuição da biblioteca escolar, na perspectiva legal, parece se revelar bastante limitada. Para que o estudante compreenda tempos, fatos, relações, conflitos, sentimentos, crenças e formas distintas de estar no mundo, é fundamental dispor de livros e materiais de leitura que contemplem gêneros textuais, autorias, sistemas de pensamento e experimentações

\footnotetext{
${ }^{4}$ No documento Biblioteca escolar como espaço de produção do conhecimento: Parâmetros para bibliotecas escolares menciona, em citação e nota, o conceito de dispositivo informacional, de Ivete Pieruccini, parece embasar o texto da Resolução CFB N. 199/2018. De acordo com Pieruccini (2007) em artigo intitulado Ordem informacional dialógica: mediação como apropriação da informação: "Se, de modo abrangente, entende-se o conceito de dispositivo de informação enquanto todo e qualquer mecanismo (técnico e simbólico) capaz de promover a relação, organizar a realidade e fornecer um instrumento para o pensamento (um texto, uma mensagem fotográfica, cinematográfica, um ambiente, uma prática), é possível caracterizá-lo como um quadro semiótico que produz significados, no interior do qual o sujeito opera."
} 
estéticas diversos, inclusive contraditórios. A formação do pensamento crítico tem como exigência o exercício dialético de construção e desconstrução, de verificação de fontes e percepções divergentes, de determinações históricas e socioeconômicas e, principalmente, de conclusões e respostas perenemente provisórias.

Ademais, na constituição do acervo, é preciso considerar as especificidades de cada escola, como recortes etários e pertencimento comunitário, valorizando as características dos grupos e oferecendo conteúdos que dialoguem imediatamente com suas formas de ser e estar no mundo e mediatamente, com perspectivas que promovam conhecimentos de alteridade. Obviamente, cabe aos educadores a oferta adequada e a orientação para a leitura e a pesquisa do acervo em sua diversidade e complexidade, uma vez que, como ressalta Saviani (2013), o conhecimento que interessa ao trabalho educativo não é buscado e apropriado espontaneamente por crianças e adolescentes. Mesmo em abordagens mais comuns em comunidades escolares específicas, o trabalho pedagógico deve aprofundar e ressignificar narrativas e conhecimentos aparentemente triviais. Tendo isso em vista, é importante que os profissionais, especialmente o bibliotecário, tenham formação específica.

A presença do profissional bibliotecário, exigência presente no Art. 3ำ, parece, no corpo da Lei, estar vinculada exclusivamente às orientações de guarda, preservação, organização e funcionamento da biblioteca, posto serem essas as únicas recomendações relacionadas à realização da ação bibliotecária. Nesse quesito, a resolução amplia o entendimento da atuação do bibliotecário, apresentando os tipos de serviços e atividades que devem ser desenvolvidos pela biblioteca, como consulta no local, empréstimo domiciliar, atividades de incentivo à leitura e orientação à pesquisa escolar.

No viés do trabalho educativo, o educador, isto é, o professor, o bibliotecário, é central na formação dos estudantes, sendo os responsáveis pela apresentação e exploração de conteúdos (autores, títulos, sistemas de pensamento, experimentações estéticas) que contribuam para a compreensão do sujeito, individual e coletivamente, em sua historicidade e concretude. Assim, os serviços técnicos biblioteconômicos (desenvolvimento, tratamento e organização do acervo; regras de funcionamento; serviço de referência) devem estar ancorados em um projeto de educação, tornando-se forma de realização de uma proposta, e não fechados em si mesmos. Dito de outra maneira, a técnica deve estar a serviço do trabalho educativo, criando condições para que ele se realize de maneira abrangente e aprofundada. Por isso, é grave que a Lei n. 12.244/2010 não vincule, explicitamente, a biblioteca escolar ao projeto pedagógico e educativo da escola.

Nessa perspectiva, a presença obrigatória do bibliotecário só se justifica, para além da defesa corporativa do mercado, se constituir contribuição efetiva ao trabalho educativo, o que 
tem como exigência uma formação que esteja sustentada em reflexão sobre aspectos sociais, históricos e econômicos da Educação e de seus sujeitos concretos.

\section{Conclusões}

A Lei n. $12.244 / 2010$ é frágil no que toca à efetividade da biblioteca escolar no trabalho educativo, especialmente porque, implicitamente, concebe a ação bibliotecária como corpo separado do projeto pedagógico da escola. Tal como preconizada na Lei e na Resolução CFB, a ação bibliotecária nas escolas tende a não contribuir para a participação de estudantes na cultura escrita, criando as condições para a apropriação do conhecimento e das narrativas produzidas pela humanidade ao longo do tempo e do espaço.

A presença obrigatória do bibliotecário deveria sustentar-se na convicção de que um profissional especializado contribui substancialmente com o trabalho educativo e não apenas na realização de serviços técnicos isolados e independentes de todo o projeto pedagógico da escola em que a biblioteca está inserida.

Vale destacar que a Resolução CFB n. 199/2018 cumpre a missão de ampliar, por meio de detalhamento, dentro dos limites da Lei n. $12.244 / 2010$, aspectos importantes da biblioteca escolar, como a existência de espaço físico e a importância de garantia de acessibilidade. No entanto, falha como instituição representativa de classe ao não implicar a biblioteca e o bibliotecário na construção e na realização de um projeto de educação, valorizando e fortalecendo a Biblioteconomia como campo de atuação na Educação.

É curioso que o Programa Nacional Biblioteca da Escola (PNBE), o maior e mais importante programa público para bibliotecas escolares, não seja considerado motivador e estruturador de projetos nas bibliotecas no corpo da Lei e na Resolução CFB, uma vez que estava em pleno funcionamento quando ela foi sancionada e foi, até 2015, em grande medida, a única forma de renovação e ampliação de acervo bibliográfico na maioria das escolas públicas brasileiras.

É fundamental que o ensino e a pesquisa em Biblioteconomia, especialmente em disciplinas e linhas de pesquisa que tenham como tema a biblioteca escolar, contemplem estudos sobre Educação e Pedagogia, tema importante, também, na formação de professores e pedagogos, que atuarão nesse campo.

Em agosto de 2018, a deputada federal Laura Carneiro, do Rio de Janeiro, apresentou o Projeto de Lei n. 9.484/2018, que altera a Lei n. 12.244 em quatro pontos: revê o conceito de biblioteca escolar; propõe a criação do Sistema Nacional de Bibliotecas Escolares; estabelece novo prazo para o cumprimento da Lei, acompanhando a vigência do Plano Nacional de Educação, isto é, 2024; e prevê sanções aos sistemas de ensino que não cumprirem a Lei. 
Embora estabeleça a vinculação da biblioteca escolar com o processo de ensino e aprendizagem e seu compromisso com a leitura e a escrita, as proposições do Projeto de Lei não alteram significativamente o teor da Lei n. 12.244, consolidando a concepção de biblioteca escolar como um espaço da escola ("espaço de recursos educativos", "espaço de estudo, encontro e lazer") e não como parte de seu projeto educativo. No entanto, sua justificativa aponta para o caráter de letra-morta que acompanha a Lei: a dois anos do prazo estabelecido para seu cumprimento, o Censo Escolar 2017, realizado pelo Instituto Nacional de Estudos e Pesquisas Educacionais Anísio Teixeira, revela números preocupantes relativos a bibliotecas escolares no país, tanto na rede pública, quanto na privada ${ }^{5}$. E o pior: o investimento financeiro para a criação de bibliotecas escolares continua na ordem dos "esforços progressivos" dos sistemas de ensino do país, que poderão ser punidos se não cumprirem a Lei.

\section{Referências}

CONSELHO FEDERAL DE BIBLIOTECONOMIA. Resolução CFB n. 199, de 3 de julho de 2018. Dispõe sobre os parâmetros a serem adotados para a estruturação e o funcionamento das Bibliotecas Escolares. Brasília, $2018 . \quad$ Disponível em <http://repositorio.cfb.org.br/handle/123456789/1313> Acesso em: 10 out. 2018.

DUARTE, Newton. Lukács e Saviani: a ontologia do ser social e a pedagogia histórico-crítica. In: SAVIANI, Dermeval; DUARTE, Newton. Pedagogia histórico-crítica e luta de classes na educação escolar. Campinas, SP: Autores Associados, 2012.

GRUPO DE ESTUDOS EM BIBLIOTECA ESCOLAR. Biblioteca escolar como espaço de produção do conhecimento: parâmetros para a biblioteca escolar. Belo Horizonte: Autêntica, 2010.

PIERUCCINI, Ivete. Ordem informacional dialógica: mediação como apropriação da informação. In: ENCONTRO NACIONAL DE PESQUISA EM CIÊNCIA DA INFORMAÇÃO, 8., 2007, Salvador Anais... Salvador: PPGCI/UFBA; ANCIB, 2007. Disponível em: <http://www.enancib.ppgci.ufba.br/artigos/GT3--159.pdf>. Acesso em: 10 out. 2018.

SAVIANI, Dermeval. Pedagogia histórico-crítica. Campinas, SP: Autores Associados, 2013.

\footnotetext{
${ }^{5} \mathrm{Na}$ Educação Infantil, 29,7\% das instituições públicas e 67,7\% das privadas contam com biblioteca; no Ensino Fundamental, as bibliotecas estão presentes em $38,9 \%$ das escolas públicas e em $82,2 \%$ da rede privada; no Ensino Médio, os números são, respectivamente, $85,9 \%$ e $92,5 \%$. Vale ressaltar que essas informações se referem ao país e que há diferenças significativas se observadas as situações individuais de cada região.
} 